\title{
Estudo Teórico de Propriedades Geométricas e Eletrônicas da Nimesulida no Vácuo Utilizando Dinâmica Molecular de Car-Parrinello
}

\author{
Eduardo C. Vaz, Ademir J. Camargo \& Solemar S. Oliveira
}

\section{Introdução}

O nimesulida é um fármaco da classe dos antiinflamatórios não-esteroides (AINES) e atua inibindo a biossíntese de prostaglandinas, através de um bloqueio competitivo da enzima ciclooxigenase (COX) e também diminuindo a formação de radicais livres em nível da cascata do ácido araquidônico, impedindo a formação de eicosanoides, combatendo, assim, os processos inflamatórios, dores e febre ${ }^{1,2}$.

Realizamos a dinâmica de Car-Parrinello no vácuo objetivando analisar as propriedades geométricas da molécula. Para comparação, também realizamos cálculos de Teoria do Funcional de Densidade (DFT), e analisamos a estrutura eletrônica. Comparamos nossos resultados com dados experimentais obtidos por difração de raios-X.

Modificações em sua estrutura molecular foram listadas na literatura provando um maior efeito antiinflamatório do nimesulida ${ }^{3-5}$. Tais modificações juntamente dos resultados obtidos serão utilizados para estudos de uma dinâmica em sistema aquoso focando melhorias na sua farmacodinâmica.

\section{Metódos}

Para os cálculos, a molécula primeiramente foi otimizada geometricamente e minimizada sua função de onda com o auxílio do algoritmo Steepest Descent.
A molécula estabilizada foi utilizada como input para os cálculos em todos os métodos. Para Car-Parrinello, utilizou-se o funcional PBE com cálculos realizados com o auxílio do programa Quantum Espresso. Para o método de DFT os cálculos com base $6-31+\mathrm{g}(\mathrm{d}, \mathrm{p})$ foram realizados com o auxílio do programa Gaussian09.

\section{Resultados e Discussões}

Os resultados da dinâmica mostraram-se positivos, confirmando que a molécula possui comportamento estável.

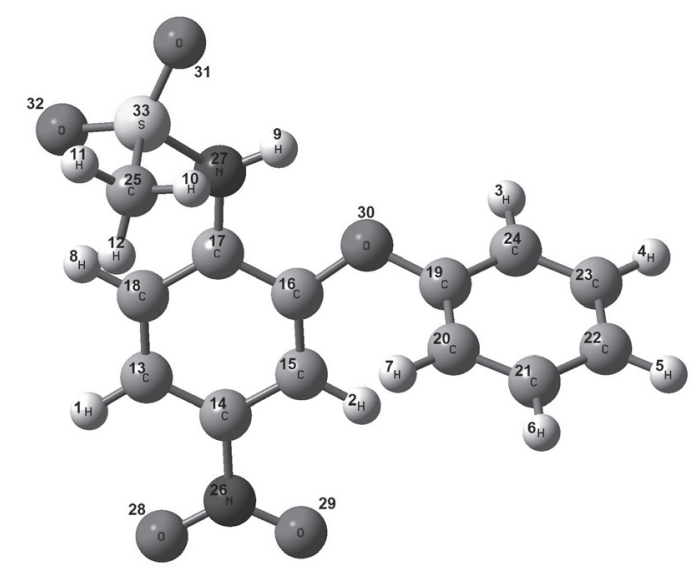

Figura 1: Molécula de Nimesulida com átomos respectivamente enumerados. 
Os resultados também mostraram que a molécula manteve a separação energia entre os subníveis eletrônico e iônico durante toda a simulação, como pode ser observado no gráfico:

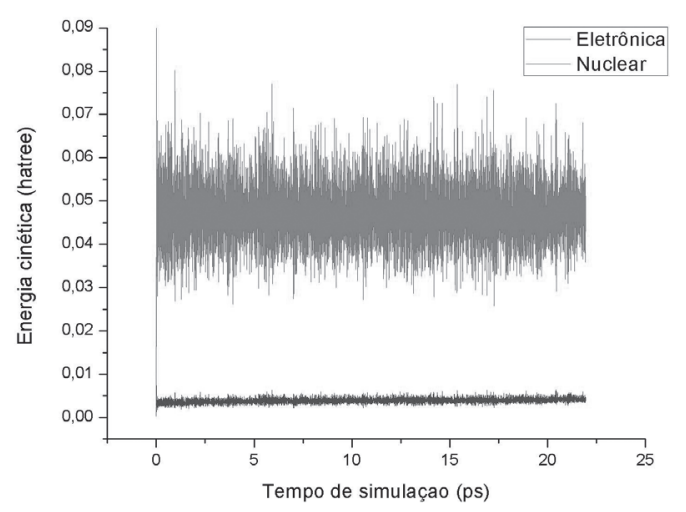

Gráfico 1: Separação adiabática dos subsistemas nuclear e eletrônico para a simulação da molécula de nimesulida.

Por meio de DFT pode-se observar as propriedades eletrônicas do nimesulida, tais como mapa de potencial eletrostático (MEP) e orbitais HOMO-LUMO.
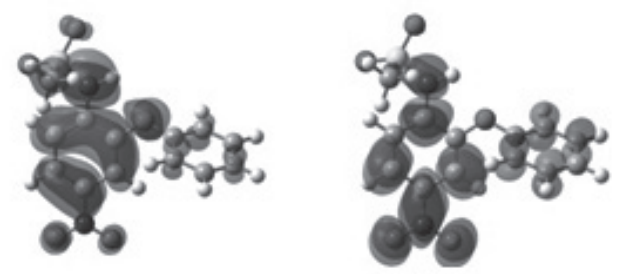

Figura 2: Orbitais HOMO-LUMO.
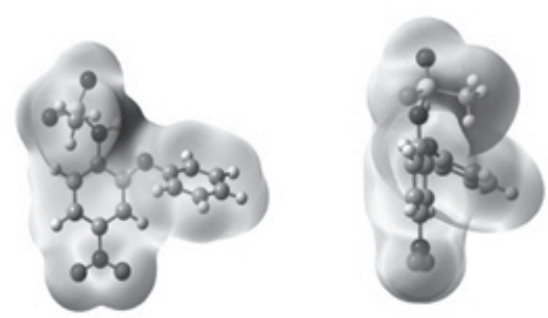

Figura 3: Mapa de potencial eletrostático (MEP).
As comparações dos parâmetros geométricos entre os métodos teóricos e os resultados experimentais estão expressos nos gráficos abaixo:

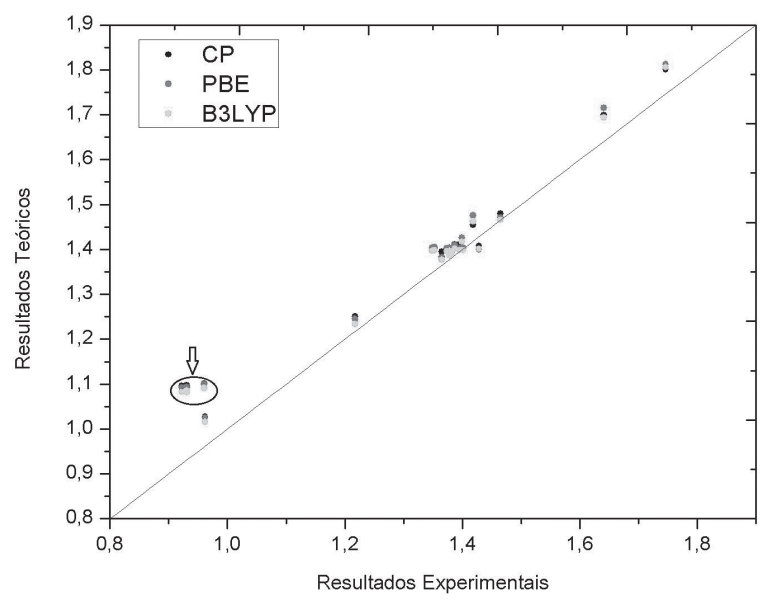

Gráfico 2: Gráfico comparativo de comprimentos de ligação $(\AA)$ entre resultados teóricos e experimentais.

Ao observar o gráfico 2, verificamos que havia um grupo de valores que mais se distanciava da reta em relação aos outros (pontos destacados no gráfico). Ao analisarmos esses valores, verificamos que se trata de uma possível repulsão eletrônica $\mathrm{H}-\mathrm{H}$, entre $\mathrm{H}(8)-\mathrm{H}(12), \mathrm{H}(9)-\mathrm{H}(10)$ e $\mathrm{H}(2)-\mathrm{H}(7)$. Os demais valores apresentaram um aceitável desvio padrão da reta.

Já ao observarmos o gráfico 3, verificamos que os valores de ângulo de ligação estavam bastante dispersos, mas dois grupos se destacavam mais, em relação aos outros, da reta (pontos destacados no gráfico). Ao analisarmos os valores, percebemos que se trata do efeito de eletropositividade na angulação da molécula, uma vez que os pontos que apresentaram alto desvio padrão correspondem a angulação entre $\mathrm{S}(33)-\mathrm{N}(27)-\mathrm{H}(9)$ e $\mathrm{S}_{(33)}-\mathrm{N}_{(27)}{ }^{-} \mathrm{C}(17)$ (como pode ser observado no MEP). 


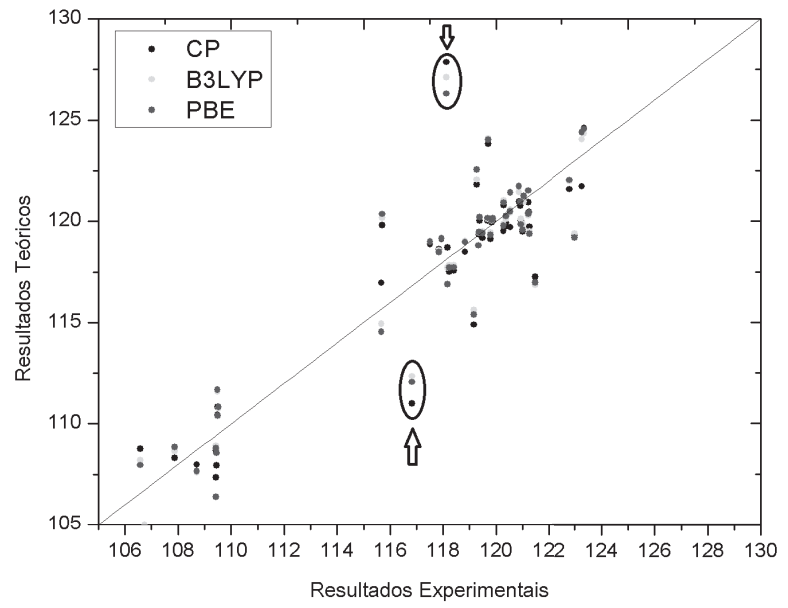

Gráfico 3: Gráfico comparativo de ângulos de ligação $\left({ }^{\circ}\right)$ entre resultados teóricos e experimentais.

\section{Conclusões}

Por meio dos resultados pode-se observer as regiões as quais o solvente provavelmente irá interagir. A probabilidade de interação é maior devido à presença de uma região eletropositiva na molécula e do posicionamento do orbital LUMO. Tal região tem maior facilidade em liberar próton, facilitanto também a interação de um solvente com a molécula.

Pode-se também comparar e verificar qual dos métodos possui maior acurácia quando comparado aos resultados experimentais a nível de parâmetros geométricos.

\section{Agradecimentos}

Gostaria de agradecer à Universidade Estadual de Goiás (UEG), por meio do Programa de Auxílio-Eventos (Pró-Eventos) pela concessão da bolsa que possibilitou minha participação no evento.

\section{Referências}

1. L. Cullen, L. Kelly, S.O. Konnor, D.J. Fitzgerald, J. Pharmacol. Exp. Ther. 287(1998) 578.

2. Dubois R, Abramson S, Crofford L et al - Cyclooxigenase in biology and disease. Faseb J. 1998;12:1063-1088,.
3. Bhattacharya, K. Kankanala, S. Pal, A. K. Mukherjee a, Journal of Molecular Structure. 975 (2010) 40-46.

4. C. Michaux, C. Charlier, F. Julémont, X. de. Leval, J. -M. Dogné, B. Pirotte, F.Durant, Eur. J. Med. Chem. 40 (2005) 1316.

5. T. Inaba, K. Tanaka, R. Takeno, H. Nagaki, C. Yoshida, S. Takano, Chem. Pharm. Bull. 48 (2000) 131.

6. CAR \& PARRINELLO. Phys. Rev. Lett., v. 55, n. 22, p. 24712474, 1985.

7. GAUSSIAN 09, Revision D.01, Frisch M. J. et al. Gaussian, Inc., Wallingford CT, 2009.

\section{Eduardo C. Vaz, Ademir J. Camargo \& Solemar S. Oliveira*.}

Universidade Estadual de Goiás (UEG) - Câmpus de Ciências Exatas e Tecnológicas (CCET)

*E-mail: solemar@ueg.br. 